\title{
Suppressive effect mediated by human adipose-derived stem cells on $T$ cells involves the activation of JNK
}

\author{
YINMIN WANG ${ }^{*}$, XIUXIA WANG ${ }^{*}$, XIANYU ZHOU, ZHU ZHU, JUN YANG and FEI LIU \\ Department of Plastic and Reconstructive Surgery, Shanghai Ninth People's Hospital, \\ Shanghai Jiao Tong University School of Medicine, Shanghai 200011, P.R. China
}

Received July 13, 2018; Accepted October 19, 2018

DOI: $10.3892 /$ ijmm.2018.3953

\begin{abstract}
Adipose-derived stem cells (ADSCs) have an immunomodulatory role in vascularized composite tissue allo-transplantation (VCA). However, the specific effects of ADSCs on lymphocytes remain to be fully elucidated. The present study examined the changes in $\mathrm{T}$ cells co-cultured with ADSCs in terms of the proliferation by Cell Counting Kit-8 assay, cell cycle profile and apoptosis by flow cytometry, inflammatory cytokine production by polymerase chain reaction and ELISA, in addition to the expression of survival proteins by western blotting. The ADSCs reduced the viability of Jurkat $\mathrm{T}$ cells and downregulated the transcription of tumor necrosis factor- $\alpha$ and transforming growth factor- $\beta 1$. Co-culture with ADSCs also induced apoptosis and increased the levels of phosphorylated c-Jun N-terminal kinase in the $\mathrm{T}$ cells. Taken together, these findings confirmed that ADSCs modulate the host immune response by suppressing $\mathrm{T}$ cells.
\end{abstract}

\section{Introduction}

The allo-transplantation of vascularized composite tissue (VCA) has been increasingly used in recent years to reconstruct tissues following amputation or severe injury $(1,2)$. However, the immunosuppressive agents that are administered

Correspondence to: Professor Jun Yang or Dr Fei Liu, Department of Plastic and Reconstructive Surgery, Shanghai Ninth People's Hospital, Shanghai Jiao Tong University School of Medicine, 639 Zhi Zao Ju Road, Shanghai 200011, P.R. China

E-mail: yj55569@hotmail.com

E-mail: plasticliu@hotmail.com

${ }^{*}$ Contributed equally

Abbreviations: ADSCs, adipose-derived stem cells; VCA vascularized composite allotransplantation; JNK, c-Jun N-terminal kinase; MSCs, mesenchymal stem cells; PBMCs, peripheral blood mononuclear cells; FBS, fetal bovine serum; FITC, fluorescein isothiocyanate; PI, propidium iodide; DMSO, dimethyl sulfoxide

Key words: adipose-derived stem cells, transplantation, apoptosis, T cell post-transplantation may cause life-threatening complications, including nephrotoxicity, opportunistic infections and tumorigenesis (3). The cumulative side effects of chronic immunosuppression outweigh the benefits of VCA. In the last decade, cellular therapy has attracted increased attention in the field of allo-transplantation. Mesenchymal stem cells (MSCs), particularly adipose-derived stem cells (ADSCs), can regulate the host immune response to allografts and, in addition to immunosuppressants, improve graft survival $(4,5)$.

The combination therapy of MSCs and immunosuppressants induces immune tolerance to VCA, indicating that a cellular component can reduce the dependency on immunosuppressants in maintaining allografts. However, cell-based therapy also has safety concerns, including the increased risk of infection during ex vivo expansion and cell aggregation during systematic infusion (6,7). Therefore, it is essential to understand the interactions between ADSCs and host immune cells in order to improve the outcomes of cellular therapy in allo-transplantation.

ADSCs secrete immunomodulatory cytokines, including prostaglandin E2 (PGE-2), which inhibit the proliferation of peripheral blood mononuclear cells (PBMCs) in a mixed lymphocyte reaction (8), and express higher levels of cyclooxygenase-2 (COX-2) and indoleamine-2,3dioxygenase when co-cultured with lymphocytes or pro-inflammatory cytokines (9). In addition, ADSCs and other MSCs regulate the function of T cells, the major driver of allo-rejection, and dendritic cells and macrophages during allo-transplantation $(10,11)$.

The studies performed so far on the mechanisms of ADSC-mediated immunosuppression have not analyzed the molecular changes induced by ADSCs in lymphocytes. The aim of the present study was to determine the effect of ADSCs on T cells; to this end, ADSCs were isolated from adipose tissues and their interaction with the human Jurkat $\mathrm{T}$ cell line was investigated.

\section{Materials and methods}

Isolation and expansion of ADSCs, and co-culture with Jurkat cells. The human ADSCs were cultured as described previously (12). Briefly, adipose tissue was obtained by liposuction of the abdominal wall from three different donors (samples 1, 2 and 3; females aged 36, 54 and 56 years; 
Shanghai 9th People's Hospital, Shanghai, China), who had provided informed consent. The tissues were digested in $0.01 \%$ collagenase IV (Roche Diagnostics GmbH, Mannheim, Germany) for $1 \mathrm{~h}$, washed twice with PBS, and seeded in $10-\mathrm{cm}$ culture dishes at the density of $1 \times 10^{5}$ cells $/ \mathrm{ml}$ with low-glucose Dulbecco's modified Eagle's medium (DMEM) supplemented with $10 \%$ fetal bovine serum (FBS; ScienCell Research Laboratories, Inc., San Diego, CA, USA), 100 U/ml penicillin and $100 \mathrm{mg} / \mathrm{ml}$ streptomycin (Gibco; Thermo Fisher Scientific, Inc., Waltham, MA, USA). The cells were cultured at $37^{\circ} \mathrm{C}$ under $5 \% \mathrm{CO}_{2}$ until they reached $80-90 \%$ confluence, following which they were dissociated with $0.05 \%$ Trypsin-EDTA and passaged. The cells of passages 2-5 were combined, and used for further characterization and in vitro differentiation. The ADSCs were identified by immunedetection of surface CD29 (1:100, cat. no. B195249), CD44 (1:100, cat.no. B162932), CD90 (1:100, cat.no. B205317), CD34 (1:100, cat. no. B203565) and CD45 (1:100, cat. no. B215193) (all BioLegend, Inc., San Diego, CA, USA). The cells were stained with the labeled antibodies for $15 \mathrm{~min}$ in the dark at $4^{\circ} \mathrm{C}$ and analyzed using the BD FACSCalibur flow cytometer (BD Biosciences, San Jose, CA, USA). Adipogenesis, osteogenesis and chondrogenesis were induced by suitable differentiation media (human adipose-derived stem cell adipogenic differentiation medium, HUXMD-90031; human adipose-derived stem cell osteogenic differentiation medium, HUXMD-90021; human adipose-derived stem cell chondrogenic differentiation medium, HUXMD-9004; all Cyagen Bioscience, Inc., Guangzhou, China) at $37^{\circ} \mathrm{C}$ under $5 \% \mathrm{CO}_{2}$ for $>28$ days, and the ensuing differentiated cells were identified by staining with oil red, alizarin red and alcian blue, respectively. Images were captured using an inverted microscope (Leica Microsystems GmbH, Wetzlar, Germany).

The Jurkat cells (purchased from GENE, Inc., Shanghai, China) were suspended in RPMI 1640 medium (HyClone; GE Healthcare, Logan, UT, USA) with $10 \%$ FBS, $100 \mathrm{U} / \mathrm{ml}$ penicillin and $100 \mathrm{mg} / \mathrm{ml}$ streptomycin, and seeded in $100-\mathrm{mm}$ dishes at the density of $1 \times 10^{6}$ cells each. The culture medium was replaced every second day. The ADSCs and Jurkat cells were co-cultured for subsequent experiments in the same media in a $0.4-\mu \mathrm{m}$ Transwell system (Corning Incorporated, Corning, NY, USA), wherein the ADSCs were seeded in the upper chamber and Jurkat cells in the lower chamber at the ratio of 1:5. The Jurkat cells were treated with $40 \mu \mathrm{M}$ of the JNK inhibitor SP600125 (Selleck Chemicals, Houston, TX, USA) or DMSO ( $1 \mu \mathrm{l} / \mathrm{ml}$ cell suspension) for $30 \mathrm{~min}$ at $37^{\circ} \mathrm{C}$ per the requirements of the experiment.

Proliferation, cell cycle and apoptosis assays. The effect of the ADSCs on Jurkat cell proliferation was measured using a CCK-8 (Doijndo Molecular Technologies, Inc., Kumamoto, Japan) assay according to the manufacturer's protocol. The Jurkat cells were seeded into the lower chamber of a 24-well Transwell plate at a density of $1 \times 10^{5}$ cells $/ \mathrm{ml}$ per well in $600 \mu \mathrm{l}$ medium. The upper chambers were filled with either ADSC suspension or sterile culture medium (control). The cells were cultured for 1,3 , or 5 days, and then incubated with $60 \mu \mathrm{l} \mathrm{CCK}-8$ per well at $37^{\circ} \mathrm{C}$ for $3 \mathrm{~h}$. The supernatants were collected and the absorbance was measured at $450 \mathrm{~nm}$ with a microplate reader (Molecular Devices LLC, Sunnyvale,
CA, USA). Each test sample was assayed in triplicate and the experiment was repeated three times.

For cell cycle profiling, the Jurkat cells were harvested following $24 \mathrm{~h}$ of mono- or co-culture, and fixed overnight with $70 \%$ ethanol. The cells were stained with the reagents provided in a Cell Cycle kit (Qihai Biotechnology, Shanghai, China) as per the manufacturer's protocol. To detect apoptosis, the mono- and co-cultured Jurkat cells were harvested and washed twice with phosphate-buffered saline (PBS), and stained using the FITC-Annexin V/PI Apoptosis Detection kit (BD Biosciences, Franklin Lakes, NJ, USA) as per the manufacturer's protocol. All stained samples were analyzed by flow cytometry (BD Biosciences, San Jose, CA, USA), and the ModFit LT v2.0 program (BD Biosciences).

Reverse transcription-quantitative polymerase chain reaction $(R T-q P C R)$ analysis. Total RNA was extracted from the Jurkat cells harvested following $48 \mathrm{~h}$ of mono- or co-culture using an RNA isolation kit (Takara Bio, Inc., Otsu, Japan). The purity of the RNA was evaluated by calculating the A260/A280 ratio, and samples with ratios between 1.8 and 2.0 were used for further analysis. The mRNA was reverse transcribed into cDNA using the PrimeScript ${ }^{\mathrm{TM}}$ II First Strand cDNA Synthesis kit (Takara Bio, Inc.). The RT-qPCR analysis was accomplished with a SYBR-Green PCR Master mix kit (Applied Biosystems; Thermo Fisher Scientific, Inc., MA, USA) containing $2 \mu \mathrm{l}$ cDNA and $0.5 \mu \mathrm{l}$ of each primer $(10 \mu \mathrm{M})$, according to the manufacturer's protocol. The following primer pairs were used for gene amplification: TGF- $\beta 1$, forward 5'-ACACCAACTATTGCTTCAG-3' and reverse 5'-TGTCCA GGCTCCAAATG-3'; TNF-a, forward 5'-CTCGAACCCCGA GTGACAAG-3' and reverse 5'-TGAGGTACAGGCCCTCT GAT-3'; $\beta$-actin, forward 5'-AAGCAGGAGTATGACGAG TCCG-3' and reverse 5'-GCCTTCATACATCTCAAGTTGG-3', with the following thermal cycling conditions for 40 cycles in total: $10 \mathrm{~min}$ at $95^{\circ} \mathrm{C} ; 15 \mathrm{sec}$ at $95^{\circ} \mathrm{C}$; and $30 \mathrm{sec}$ at $60^{\circ} \mathrm{C}$. The relative gene expression levels were calculated using the $2^{-\Delta \Delta \mathrm{Cq}}$ method (13), and normalized against those of $\beta$-actin. Three independent experiments were performed.

ELISA. After $72 \mathrm{~h}$, the supernatants were collected from the mono- and co-cultured Jurkat cells and stored at $-80^{\circ} \mathrm{C}$ until use. The levels of TGF- $\beta 1$ were measured using an ELISA kit (R\&D Systems, Inc., Minneapolis, MN, USA) according to the manufacturer's protocol.

Western blotting. Total protein was extracted from the Jurkat cells harvested following 24,48 or $72 \mathrm{~h}$ of co-culture with RIPA lysis buffer as described previously (14). The nuclear proteins were extracted with NE-PER nuclear and cytoplasmic extraction reagents (Pierce; Thermo Fisher Scientific, Inc.) from the 48 and $72 \mathrm{~h}$ co-cultured cells. Equal quantities of protein $(40 \mu \mathrm{g})$ per sample were loaded on an $12 \%$ SDS-polyacrylamide gel, electrophoresed and transferred onto a PVDF membrane and blocked with TBS with Tween-20 containing 5\% non-fat dry milk for $1 \mathrm{~h}$ at room temperature. The membranes were probed with primary antibodies against phosphorylated (p)-P65 (1:2,000, cat. no. AF2006, Affinity Biosciences, Cambridge, UK), P65 (1:2,000, cat. no. 10745-1-AP, ProteinTech Group, Inc., Wuhan, 

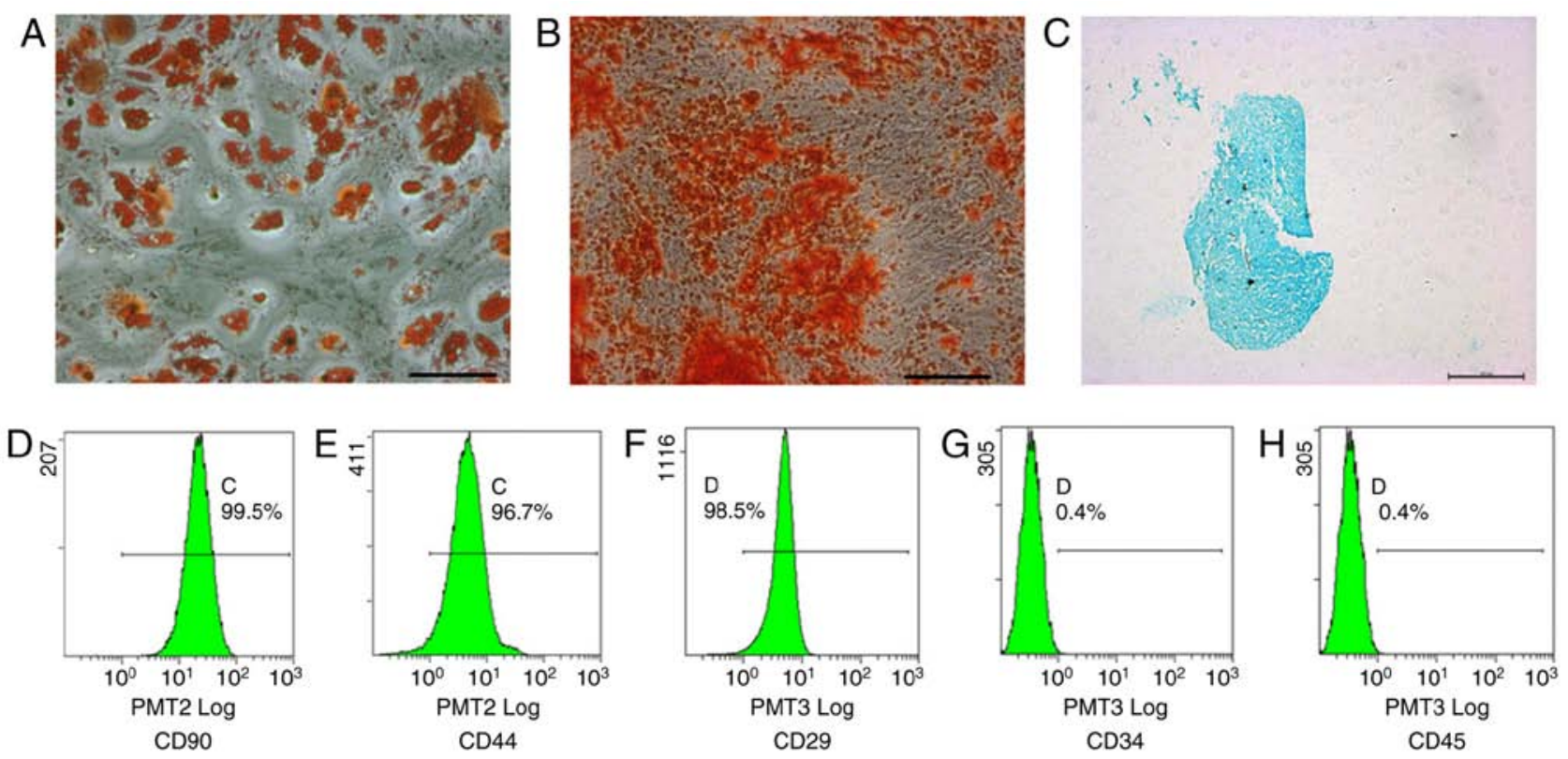

Figure 1. Characterization of ADSCs and their differentiation capacity. Representative images of (A) alizarin red-stained osteocytes following 4-week induction (scale bar $=50 \mu \mathrm{m}$ ), (B) oil red O-stained adipocytes following 3-week induction (scale bar=50 $\mu \mathrm{m}$ ), and (C) alcian blue-stained chondrocytes following 4-week induction (scale bar $=200 \mu \mathrm{m})$. Flow cytometric analysis of ADSCs showing the percentage of $(\mathrm{D}) \mathrm{CD}^{+}(98.7 \%),(\mathrm{E}) \mathrm{CD} 44^{+}(97.9 \%),(\mathrm{F}) \mathrm{CD} 29^{+}$ (98.4\%), (G) CD34+ (0.28\%), and (H) CD56 (0.4\%) cells. ADSCs, adipose-derived stem cells.

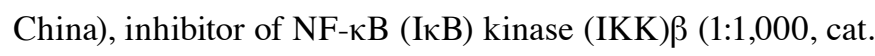
no. Ab124957, Abcam, Cambridge, MA, USA), IкB $\alpha$ (1:1,000, cat. no. 4812, Cell Signaling Technology, Inc., Danvers, MA, USA), B-cell lymphoma 2 (Bcl-2; 1:2,000, cat. no. 12789-1-AP, ProteinTech Group, Inc.), Bcl-2-associated X protein (Bax; 1:5,000, cat. no. 50599-2-IG, Protein Tech Group, Inc), JNK1/2 (1:1,000, cat. no. 9252, Cell Signaling Technology, Inc.), p-JNK1/2 (1:1,000, cat. no. 4668, Cell Signaling Technology, Inc.), extracellular signal-regulated kinase (ERK)1/2 (1:1,000, cat. no. 9102, Cell Signaling Technology, Inc.), p-ERK1/2 (1:2,000, cat. no. 4370, Cell Signaling Technology, Inc.), P38 (1:1,000, cat. no. 9212, Cell Signaling, Technology, Inc.), p-P38 (1:1,000, cat. no. 9211, Cell Signaling Technology, Inc.), mothers against decapentaplegic (Smad)2/3 (1:1,000, cat. no. AF6367, Affinity Biosciences), p-Smad2/3 (1:200, cat. no. MAB8935, R\&D Systems, Inc.) and the loading control $\beta$-actin (1:200, cat. no. BM0627, Boster Biological Technology, Wuhan, China). This step was followed by incubation with horseradish peroxidase-conjugated secondary antibodies (1:50,000, goat anti-mouse, cat no. BA1051, Boster Biological Technology) for $2 \mathrm{~h}$ at room temperature. The specific protein bands were visualized using an enhanced chemiluminescence detection kit (GE Healthcare Life Sciences, Chalfont, UK), and the ratio of the grayscale values of the target protein were calculated.

Statistical analysis. All data are presented as the mean \pm standard deviation. Statistical significance was calculated with Student's t-test and one-way analysis of variance; Tukey's multiple comparison test was used for post hoc analysis. Statistical analyses were performed using Prism 6.0 software (GraphPad Software, Inc., La Jolla, CA, USA). $\mathrm{P}<0.05$ was considered to indicate a statistically significant difference.

\section{Results}

Effect of ADSCs on Jurkat cell proliferation, cell cycle and apoptosis. The ADSCs isolated from human adipose tissue were characterized using MSC surface markers CD90, CD44, CD29, CD34 and CD45 (12). The multipotency of the ADSCs was determined by the adipogenic, osteogenic and chondrogenic differentiation assays (Fig. 1A-H).

The effect of ADSCs on Jurkat cell behavior was assessed using established proliferation, cell cycle and apoptosis assays. Although no significant differences were observed in the proliferation rates of the mono- and co-cultured Jurkat cells on days 1 and 3, the ADSC-co-cultured cells exhibited a significantly lower proliferation rate on day 5 compared with the control cells $(\mathrm{P}<0.05$; Fig. 2A). Following $24 \mathrm{~h}$ of co-culture with ADSCs, the proportion of Jurkat cells in the $\mathrm{G}_{0} / \mathrm{G}_{1}$ and $\mathrm{G}_{2} / \mathrm{M}$ phases increased significantly and there was a concomitant decrease in the proportion of cells in the $S$ phase compared with the control cells (Fig. 2B). Finally, the Jurkat cells co-cultured with ADSCs for $48 \mathrm{~h}$ exhibited significantly higher apoptotic rates than the control cells (Fig. 3A-D). The Jurkat cells co-cultured with ADSCs for $48 \mathrm{~h}$ also showed significantly higher levels of pro-apoptotic Bax and lower levels of anti-apoptotic Bcl-2 compared with the control cells (Fig. 3E). Taken together, the ADSCs suppressed Jurkat cell proliferation by arresting them at the $G_{0} / G_{1}$ and $G_{2} / M$ phases, and inducing apoptosis.

Effect of ADSCs on Jurkat cell cytokine secretion. The mRNA and protein levels of TNF- $\alpha$ and TGF- $\beta 1$ were measured in the Jurkat cells co-cultured with ADSCs by RT-qPCR and ELISA analyses, respectively. Compared with the control cells, the mRNA levels of TNF- $\alpha$ and TGF- $\beta 1$ were significantly decreased in the co-cultured cells at $48 \mathrm{~h}$, whereas the 

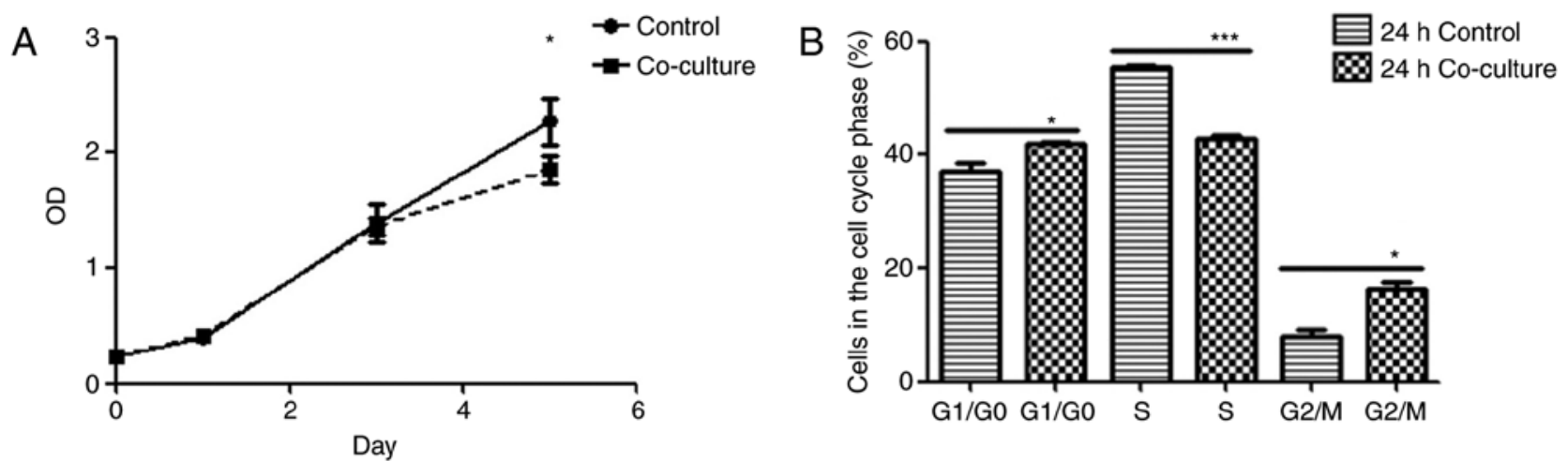

Figure 2. Proliferation and cell cycle profile of mono- and co-cultured Jurkat cells. (A) Cell proliferation curve of Jurkat cells measured in terms of absorbance at $450 \mathrm{~nm}$, showing a significant difference on day 5 only ( $\left.{ }^{*} \mathrm{P}<0.05\right)$. (B) Distribution of adipose-derived stem cell co-cultured Jurkat cells in the different cell cycle phases following $24 \mathrm{~h}$ of culture, showing a shift from the $\mathrm{S}$ phase to the $\mathrm{G}_{1} / \mathrm{G}_{0}\left({ }^{* * * *} \mathrm{P}<0.001\right)$ and $\mathrm{G}_{2} / \mathrm{M}\left({ }^{*} \mathrm{P}<0.05\right)$ phases.
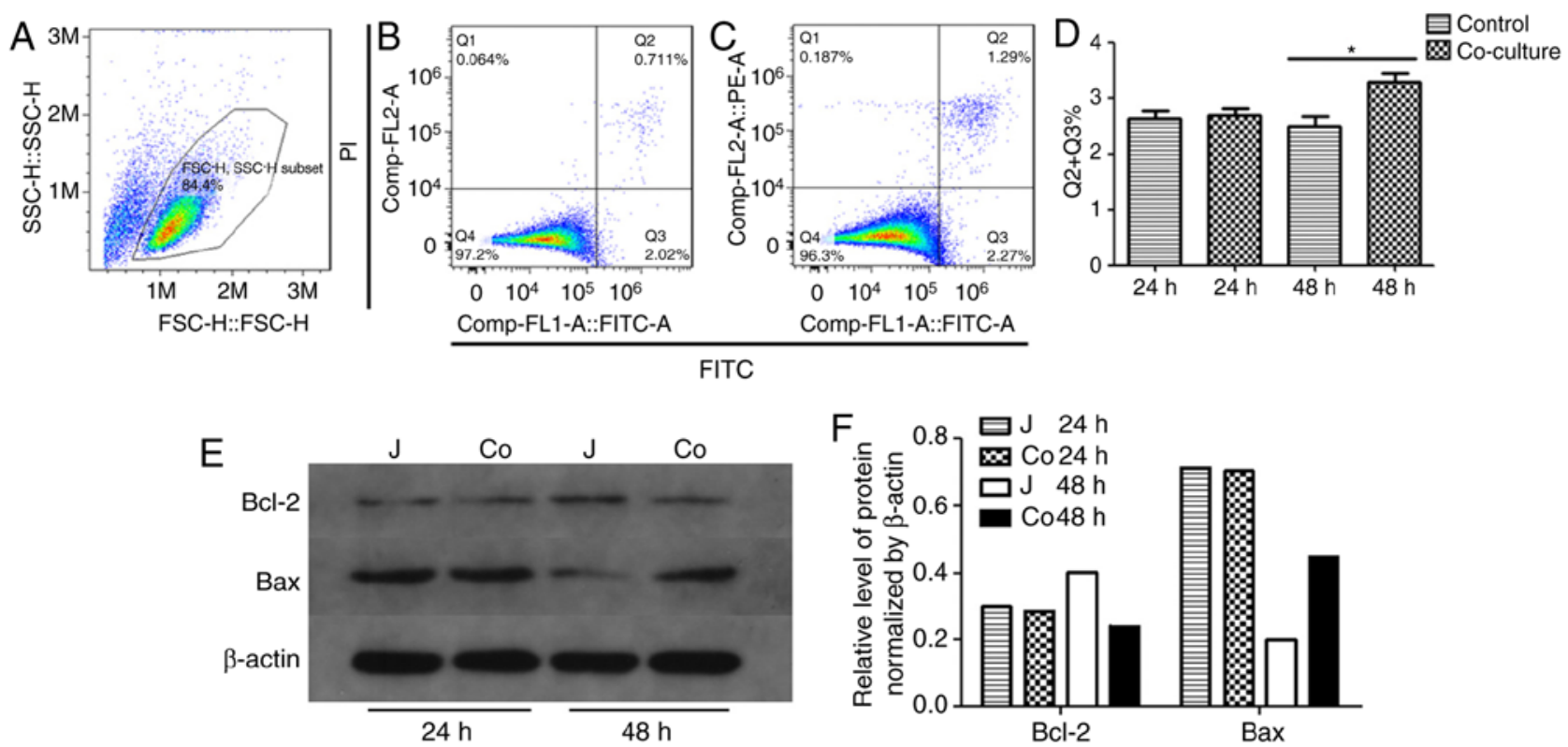

Figure 3. Apoptosis of Jurkat cells. (A) Flow cytometry gating strategy for AnnexinV/PI-stained cells. Representative images of apoptotic Jurkat cells following (B) mono-culture and (C) co-culture. (D) Comparison of the percentage of apoptotic cells in the two groups showing significant difference following $48 \mathrm{~h}$ of culture ( $\left.{ }^{*} \mathrm{P}<0.05\right)$. (E) Bcl-2 and Bax proteins in control and co-cultured cells, showing lower expression of Bcl-2 and increased expression of Bax at $48 \mathrm{~h}$. (F) Densitometric analysis of the expression of Bcl-2 and Bax, showing upregulation of Bax following $48 \mathrm{~h}$ of co-culture and downregulation of Bcl-2 following $48 \mathrm{~h}$ of co-culture. FITC, fluorescein isothiocyanate; PI, propidium iodide; Bcl-2, B-cell lymphoma 2; Bax, Bcl-2-associated X protein; J, control; co, co-cultured.

secreted levels of TGF- $\beta 1$ were significantly increased in the supernatants of the co-cultured cells at 72 h. (Fig. 4).

Regulation of Jurkat cell signaling pathways by ADSCs. In addition to the cells co-cultured with ADSCs for $48 \mathrm{~h}$ showing higher levels of pro-apoptotic Bax and lower levels of anti-apoptotic Bcl-2, the NF- $\mathrm{KB}$ p-P65 subunit levels in the cellular and nuclear fractions were marginally lower in the co-cultured cells compared with those in the control cells after $72 \mathrm{~h}$. No apparent differences were observed in the levels of $\mathrm{P} 65$, IKB $\alpha$ or IKK $\beta$ between the two groups, as well as the level of Erk, P38 and Smad2/3 (Figs. 5A-D and 6). By contrast, the level of p-JNK1/2 was higher in the co-cultured cells after $48 \mathrm{~h}$ (Fig. 6A-C). These findings indicated that the ADSCs induced apoptosis of the Jurkat cells by suppressing NF- $\mathrm{B}$ P65 subunit phosphorylation and activating the JNK signaling pathway.
ADSC induces apoptosis in Jurkat cells via the JNK pathway. In order to evaluate the role of the activation of JNK in ADSC-induced Jurkat cell apoptosis, the latter were treated with $40 \mu \mathrm{M}$ of the specific JNK inhibitor SP600125 prior to the co-culture, and the percentage of apoptotic cells was assessed. As shown in Fig. 7A-E, the inhibition of JNK in Jurkat cells significantly inhibited ADSC-induced apoptosis.

\section{Discussion}

As the prognosis of allo-transplantation is dependent on the host immune response to the allografts, reducing T cell-mediated acute rejection is vital in order to protect the allograft. The immunomodulatory effects of ADSCs observed in pre-clinical studies make it a suitable addition to routine immuno-suppressants for preventing allograft rejection $(4,5)$. Therefore, it 

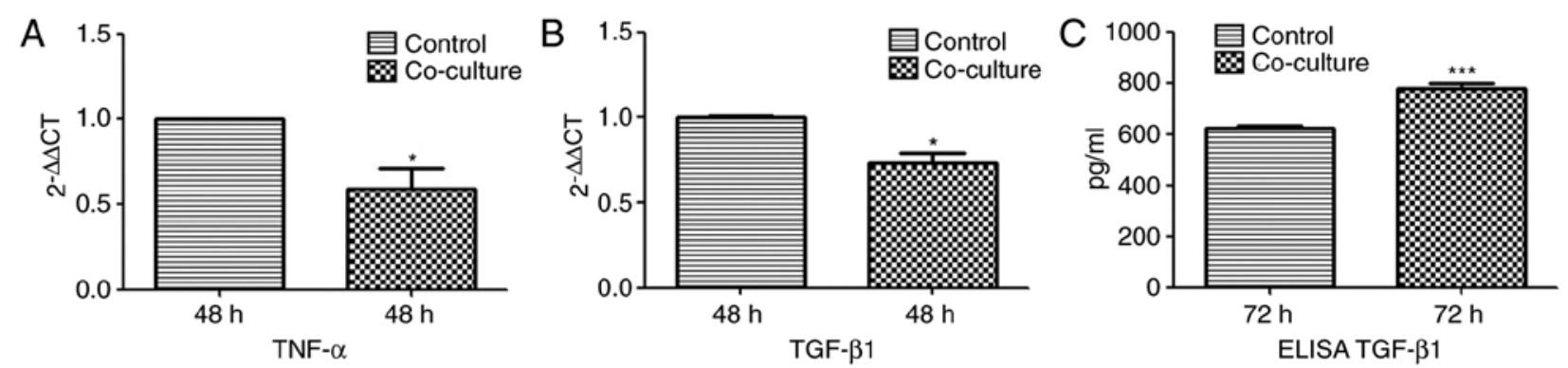

Figure 4. Expression of TGF- $\beta 1$ and TNF- $\alpha$ is induced by ADSCs. Relative mRNA expression of (A) TGF- $\beta 1$ and (B) TNF- $\alpha$ in control and co-cultured Jurkat cells, showing significant differences in the expression of the genes at $48 \mathrm{~h}$. ("P<0.05). (C) Levels of TGF $\beta 1$ in the supernatants of control and co-cultured Jurkat cells were detected by ELISA and showed significantly higher levels in the co-culture supernatant at $72 \mathrm{~h}\left({ }^{* * * *} \mathrm{P}<0.001\right)$. ELISA, enzyme-linked immunosorbent assay; TFG- $\beta 1$, transforming growth factor- $\beta 1$; TNF- $\alpha$, tumor necrosis factor- $\alpha$.
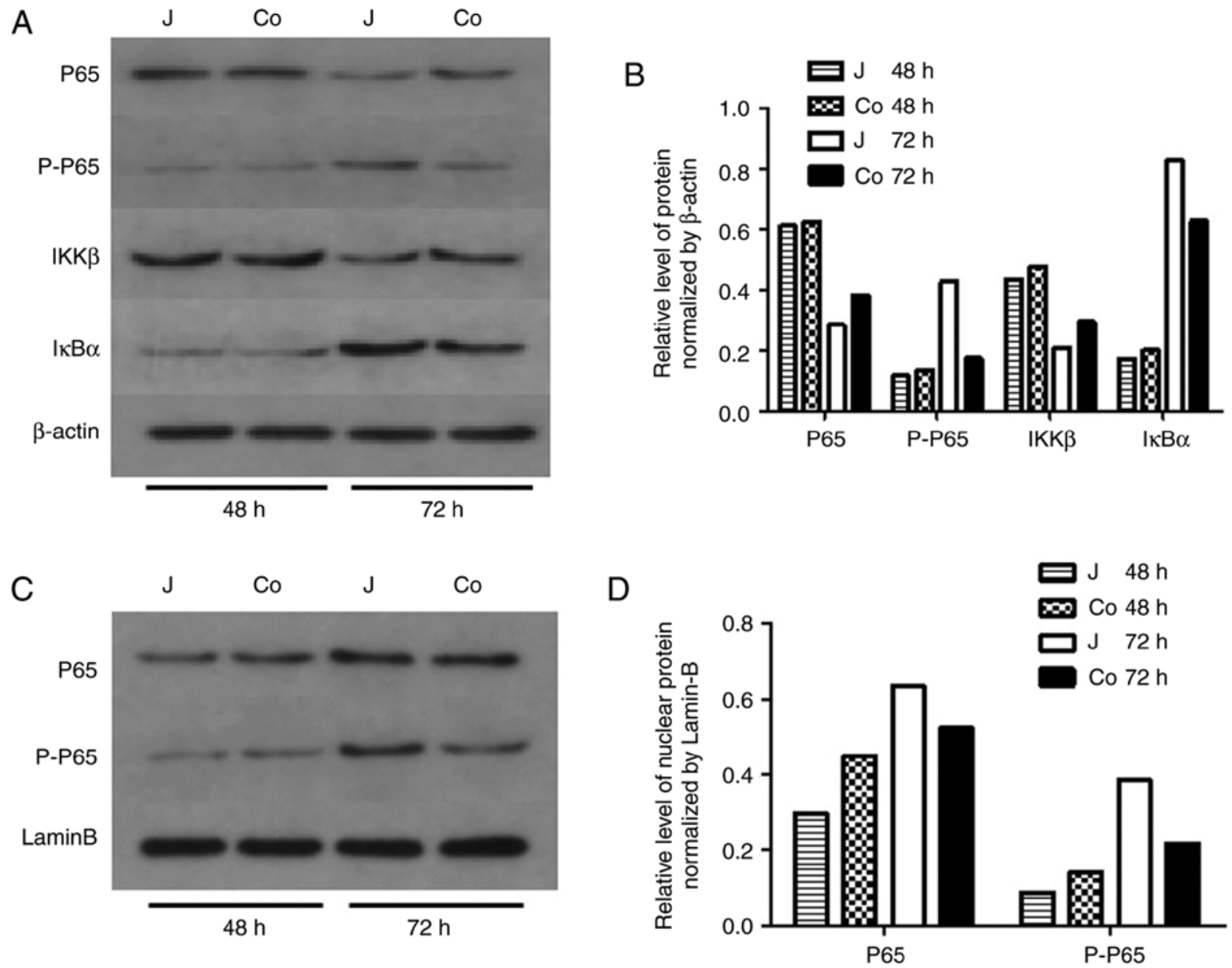

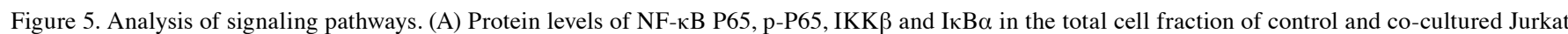
cells and (B) densitometric analysis of the western blot data. (C) Expression of NF- $\mathrm{kB}$ P65 and p-P65 in the nuclear protein of Jurkat cells and (D) densitometric

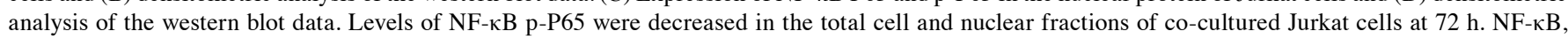

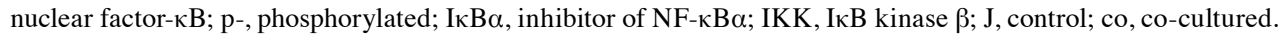

is important to determine the specific effects of ADSCs on immune cells, particularly $\mathrm{CD} 4^{+}$and $\mathrm{CD} 8^{+} \mathrm{T}$ cells, which are the major elicitors of acute and chronic rejection $(15,16)$.

Gonzalez-Rey et al (17) reported suppressive effects of human ADSCs on the proliferation of activated PBMCs and production of TNF- $\alpha$. A study on the miniature swine hind-limb model showed that the infusion of ADSCs prolonged allograft survival, increased regulatory $\mathrm{T}$ cells in allografts and blood, and decreased the levels of circulating pro-inflammatory cytokine TNF- $\alpha$ (4). In addition, Matula et al (18) reported a similar inhibitory effect of ADSCs on Jurkat T cells following 3 and 4 days of co-culture. However, Mousavi et al (19) did not report any differences in the proliferation rates of Jurkat cells cultured with or without ADSC for 2 and 3 days. In the present study, ADSC co-culture reduced Jurkat cell viability on day 5 , with no significant effects observed until 
A

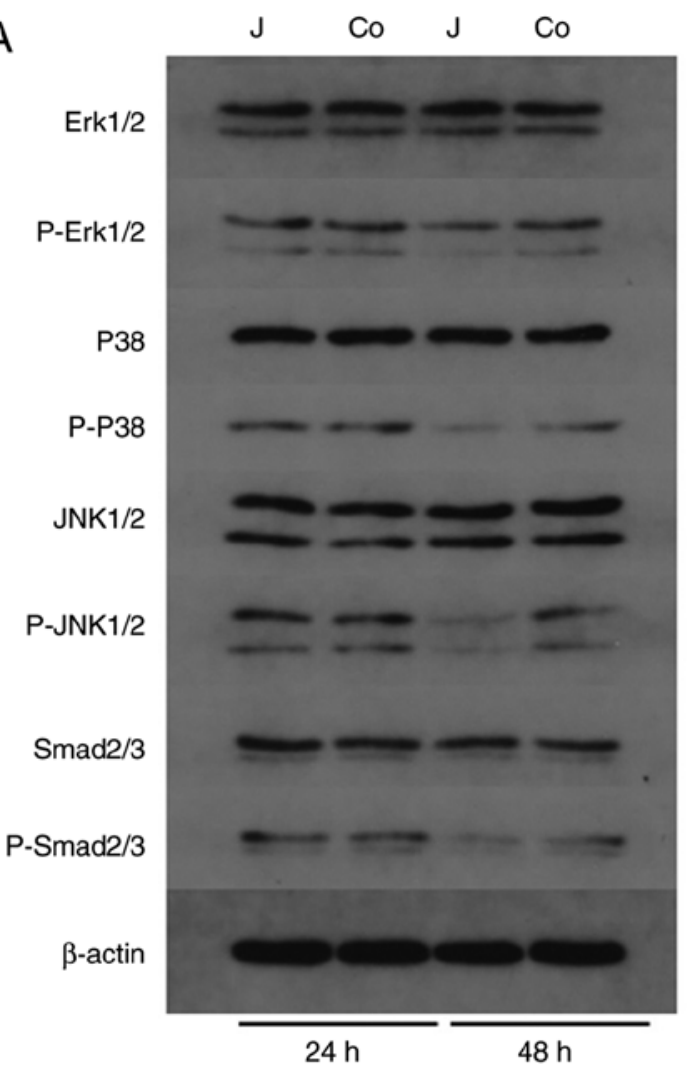

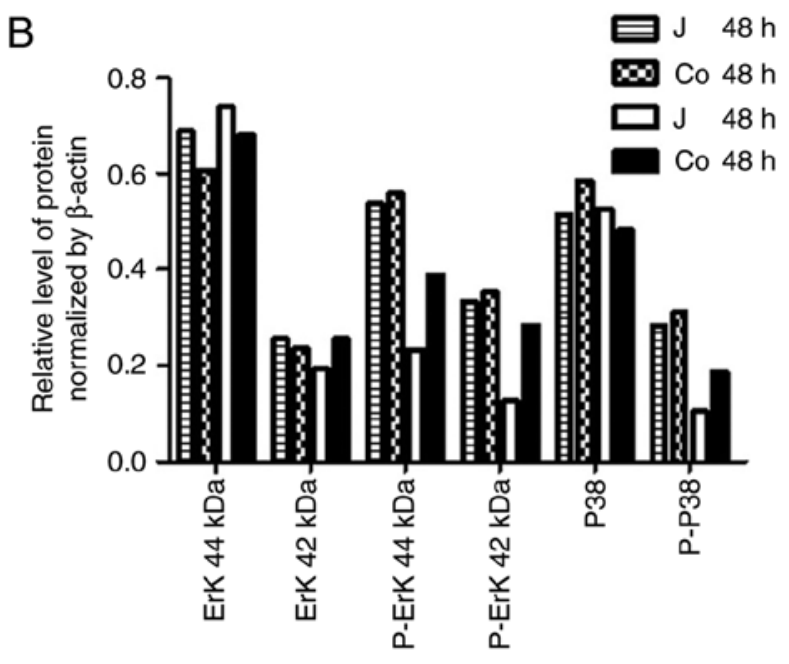

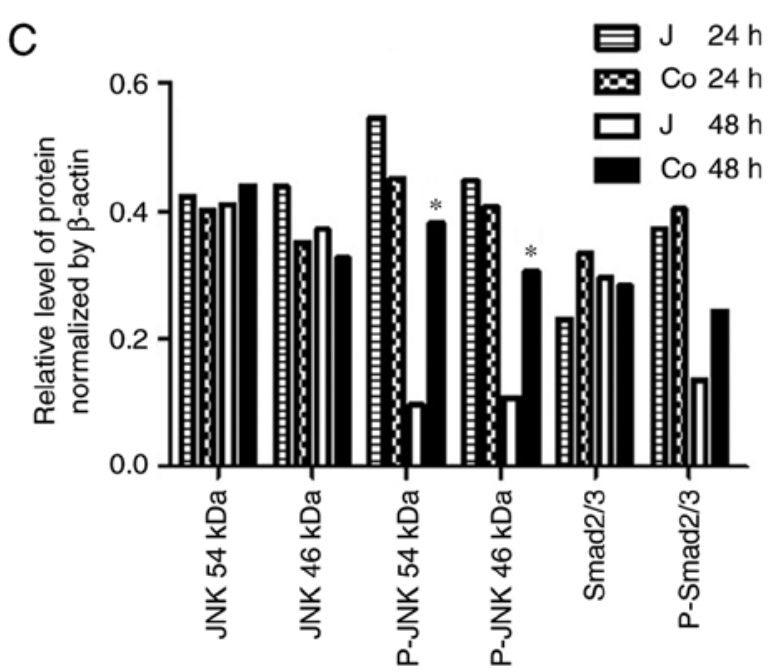

Figure 6. Signaling pathways. (A) Protein levels of Erk, p-Erk, P38, p-P38, JNK, p-JNK, Smad2/3 and P-Smad2/3 in the control and co-cultured Jurkat cells. (B) Densitometric analysis of the expression of Erk, p-Erk, P38 and p-P38. (C) Densitometric analysis of the expression of JNK, p-JNK, Smad2/3 and p-Smad2/3, showing upregulation of p-JNK following $48 \mathrm{~h}$ of co-culture compared with the control group at $48 \mathrm{~h}$. ( $\mathrm{P}<0.05 \mathrm{vs}$. $\mathrm{J} 48 \mathrm{~h}$ ). $\mathrm{J}$, control; co, co-cultured; Erk, extracellular signal-regulated kinase; JNK, c-Jun N-terminal kinase; Smad2/3, mothers against decapentaplegic; p-, phosphorylated.

day 3 , indicating a time-dependent effect of the ADSCs on Jurkat cells.

The NFAT and NF- $\kappa \mathrm{B}$ signaling pathways synergistically activate $\mathrm{T}$ cells $(20)$. $\mathrm{NF}-\kappa \mathrm{B}$ is a transcription factor that regulates the expression of inflammatory cytokines and genes essential for the proliferation and survival of T cells (21). MSCs have been shown to inhibit $\mathrm{NF}-\kappa \mathrm{B}$ signaling in responder cells (22-24). Consistent with this, the present study observed a reduction in the levels of p-p65 and its nuclear translocation in Jurkat cells co-cultured with ADSCs, thereby confirming the suppressive effect of ADSCs on T cells.

Consistent with the pro-apoptotic effects of MSCs on $\mathrm{T}$ cells reported in previous studies $(25,26)$, the present study observed increased apoptosis in the Jurkat cells co-cultured with ADSCs. Previous studies have also reported an inhibitory effect of MSCs on T cell apoptosis (27-29). This ambiguity may be the result of differences in responder cells (28), different tissue sources of MSCs (e.g. bone marrow, placenta or adipose tissue) $(27,29)$, and different T-cell stimulators (e.g., PHA or anti-Fas antibody) (27,29) used in these studies. Therefore, MSCs from different origins may affect $\mathrm{T}$ cell function via different mechanisms.
Apoptosis can be induced by either inhibiting survival signals, for example, BCL-2 as an inner mitochondrial membrane anti-apoptotic protein, or by increasing death signals, for example BAX as a pro-apoptotic effector of mitochondrial outer membrane permeabilization (30). Furthermore, Bcl-2-associated apoptosis in Jurkat cells is associated with the activation of JNK (31). The present study observed increased levels of $\mathrm{p}-\mathrm{JNK} 1 / 2$ in the co-cultured Jurkat cells, indicating the ADSC-mediated activation of JNK. The involvement of the JNK pathway in ADSC-induced apoptosis was further verified by the JNK-specific inhibitor SP600125 inhibiting apoptosis in the co-cultured Jurkat cells. However, the inhibitory effect was not complete, indicating the involvement of other pathways in ADSC-induced apoptosis. Higher levels of secreted TGF- $\beta 1$, an activator of JNK, were present in the supernatants of the co-cultured Jurkat cells. However, the mRNA levels of TGF- $\beta 1$ were significantly lower in the co-cultured Jurkat cells; it is likely that TGF- $\beta 1$ was secreted by the ADSCs and not Jurkat cells. TGF- $\beta 1$ is an important component of the ADSC secretome, and has immunosuppressive and apoptotic effects on T cells $(32,33)$. Taken together, the 

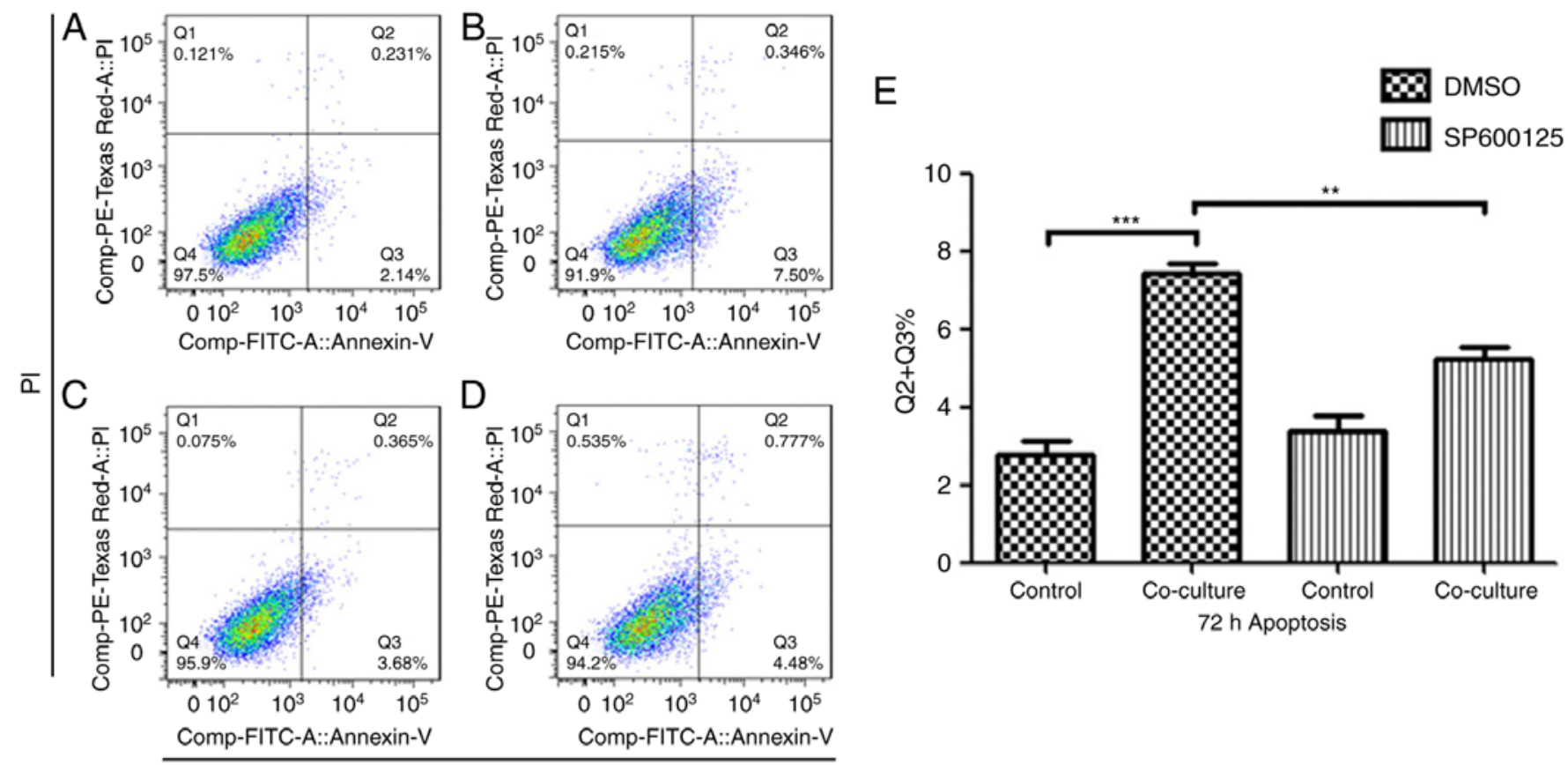

FITC

Figure 7. Effect of the JNK inhibitor SP600125 on Jurkat cell apoptosis. Representative images showing apoptosis in (A) control Jurkat cells treated with DMSO, (B) co-cultured Jurkat cells treated with DMSO, (C) control Jurkat cells treated with SP600125, and (D) co-cultured Jurkat cells treated with SP600125. (E) Tukey's multiple comparison test shows significant differences between the co-cultured and control cells treated with DMSO for $72 \mathrm{~h}$, and between the DMSO and SP600125-treated co-cultured cells $\left({ }^{* *} \mathrm{P}<0.01 ;{ }^{* * * *} \mathrm{P}<0.001\right)$. FITC, fluorescein isothiocyanate; PI, propidium iodide; DMSO, dimethyl sulfoxide; JNK, c-Jun N-terminal kinase.

ADSCs induced apoptosis in Jurkat cells by activating the JNK pathway.

MSCs have shown potential in improving transplantation outcomes (34-36). A previous study showed that the inclusion of bone marrow-derived MSCs (BMSCs) during renal transplantation improved renal function at the one-year follow-up (34). In addition, the BMSCs also reduced tubulitis, interstitial fibrosis and tubule atrophy post-transplantation (35). The immunomodulatory effects ADSCs, although evident in pre-clinical and experimental studies, have not been verified in clinical trials. In the present study, the mechanism underlying the effect of ADSC on T cells was elucidated, to further underscore the clinical potential of ADSCs in immunological diseases and transplantation, and to improve current understanding of stem cell-based therapy.

In conclusion, the present study showed that ADSCs suppressed Jurkat $\mathrm{T}$ cell viability by inducing apoptosis and cell cycle arrest by activating the JNK signaling and mitochondrial apoptotic pathways. These findings provide novel insights into the molecular mechanisms underlying the immunomodulatory effects of ADSCs, and provide an experimental basis for the clinical application of ADSCs.

\section{Acknowledgements}

The authors would like to thank the Laboratory of Tissue Engineering at Shanghai Ninth People's Hospital, Shanghai Jiao Tong University (Shanghai, China) for the provision of experimental equipment and technical guidance necessary to complete the study.

\section{Funding}

The present study was supported by the National Natural Science Foundation for Young Scholars (grant no. 81401613).

\section{Availability of data and materials}

The data used during the present study are available from the corresponding authors on reasonable request.

\section{Authors' contributions}

FL conceived and designed the experiments, and JY guided the design of the experiments. YMW and XXW performed the experiments under the direction of JY. ZZ and XYZ were involved in the completion of the experiments. YMW and XXW analyzed the data. YMW wrote the manuscript. FL and JY revised the manuscript. All the authors read and approved the final manuscript.

\section{Ethics approval and consent to participate}

All experiments were approved by the Ethics Committee of Shanghai Ninth People's Hospital, Shanghai Jiao Tong University School of Medicine (no. 2017-452-T348). The donors provided written informed consent.

\section{Patient consent for publication}

Not applicable. 


\section{Competing interests}

The authors declare that they have no competing interests.

\section{References}

1. Khalifian S, Brazio PS, Mohan R, Shaffer C, Brandacher G, Barth RN and Rodriguez ED: Facial transplantation: The first 9 years. Lancet 384: 2153-2163, 2014

2. Zuo KJ and Olson JL: The evolution of functional hand replacement: From iron prostheses to hand transplantation. Plast Surg (Oakv) 22: 44-51, 2014.

3. Bamoulid J, Staeck O, Halleck F, Khadzhynov D, Brakemeier S, Durr M and Budde K: The need for minimization strategies: Current problems of immunosuppression. Transpl Int 28: 891-900, 2015.

4. Kuo YR, Chen CC, Chen YC and Chien CM: Recipient Adipose-derived stem cells enhance recipient cell engraftment and prolong allotransplant survival in a miniature swine hind-limb model. Cell Transplant 26: 1418-1427, 2017.

5. Plock JA, Schnider JT, Zhang W, Schweizer R, Tsuji W, Kostereva N, Fanzio PM, Ravuri S, Solari MG, Cheng HY, et al: Adipose- and bone marrow-derived mesenchymal stem cells prolong graft survival in vascularized composite allotransplantation. Transplantation 99: 1765-1773, 2015.

6. Munir $\mathrm{H}$ and McGettrick HM: Mesenchymal stem cell therapy for autoimmune disease: Risks and rewards. Stem Cells Dev 24: 2091-2100, 2015.

7. Boltze J, Arnold A, Walczak P, Jolkkonen J, Cui L and Wagner DC: The dark side of the force-constraints and complications of cell therapies for stroke. Front Neurol 6: 155, 2015.

8. Cui L, Yin S, Liu W, Li N, Zhang W and Cao Y: Expanded adipose-derived stem cells suppress mixed lymphocyte reaction by secretion of prostaglandin E2. Tissue Eng 13: 1185-1195, 2007.

9. Crop MJ, Baan CC, Korevaar SS, Ijzermans JN, Pescatori M, Stubbs AP, van Ijcken WF, Dahlke MH, Eggenhofer E, Weimar W and Hoogduijn MJ: Inflammatory conditions affect gene expression and function of human adipose tissue-derived mesenchymal stem cells. Clin Exp Immunol 162: 474-486, 2010.

10. Kuo YR, Chen CC, Goto S, Lin PY, Wei FC and Chen CL: Mesenchymal stem cells as immunomodulators in a vascularized composite allotransplantation. Clin Dev Immunol 2012: 854846, 2012 .

11. Zhao Q, Ren $H$ and Han Z: Mesenchymal stem cells: Immunomodulatory capability and clinical potential in immune diseases. J Cell Immunotherapy 2: 3-20, 2016.

12. Bunnell BA, Flaat M, Gagliardi C, Patel B and Ripoll C: Adipose-derived stem cells: Isolation, expansion and differentiation. Methods 45: 115-120, 2008.

13. Livak KJ and Schmittgen TD: Analysis of relative gene expression data using real-time quantitative PCR and the 2(-Delta Delta C(T)) method. Methods 25: 402-408, 2001.

14. Hwang GS, Hu S, Lin YH, Chen ST, Tang TK, Wang PS and Wang SW: Arecoline inhibits interleukin-2 secretion in Jurkat cells by decreasing the expression of alpha7-nicotinic acetylcholine receptors and prostaglandin E2. J Physiol Pharmacol 64 535-543, 2013.

15. Liu Z, Fan H and Jiang S: CD4(+) T-cell subsets in transplantation. Immunol Rev 252: 183-191, 2013.

16. Yap M, Brouard S, Pecqueur C and Degauque N: Targeting CD8 T-cell metabolism in transplantation. Front Immunol 6: 547, 2015.

17. Gonzalez-Rey E, Gonzalez MA, Varela N, O'Valle F, Hernandez-Cortes P, Rico L, Büscher D and Delgado M: Human adipose-derived mesenchymal stem cells reduce inflammatory and $\mathrm{T}$ cell responses and induce regulatory $\mathrm{T}$ cells in vitro in rheumatoid arthritis. Ann Rheum Dis 69: 241-248, 2010.

18. Matula Z, Németh A, Lőrincz P, Szepesi Á, Brózik A, Buzás EI, Lów P, Német K, Uher F and Urbán VS: The role of extracellular vesicle and tunneling Nanotube-mediated intercellular cross-talk between mesenchymal stem cells and human peripheral T cells. Stem Cells Dev 25: 1818-1832, 2016.

19. Mousavi Niri N, Jaberipour M, Razmkhah M, Ghaderi A and Habibagahi M: Mesenchymal stem cells do not suppress lymphoblastic leukemic cell line proliferation. Iran J Immunol 6 : 186-194, 2009.
20. Bronk CC, Yoder S, Hopewell EL, Yang S, Celis E, Yu XZ and Beg AA: NF- $\mathrm{BB}$ is crucial in proximal T-cell signaling for calcium influx and NFAT activation. Eur J Immunol 44: 3741-3746, 2014

21. Reale C, Zotti T, Scudiero I, Vito P and Stilo R: Chapter nine-the $\mathrm{NF}-\kappa \mathrm{B}$ family of transcription factors and its role in thyroid physiology. In: Vitamins and Hormones. Litwack G, (ed.) Academic Press, pp195-210, 2018.

22. Letourneau PA, Menge TD, Wataha KA, Wade CE, S Cox C Jr, Holcomb JB and Pati S: Human bone marrow derived mesenchymal stem cells regulate Leukocyte-endothelial interactions and activation of transcription factor NF-Kappa B. J Tissue Sci Eng 3 (Suppl): S001, 2011.

23. Onishi R, Ohnishi S, Higashi R, Watari M, Yamahara K, Okubo N Nakagawa K, Katsurada T, Suda G, Natsuizaka M, et al: Human amnion-derived mesenchymal stem cell transplantation ameliorates dextran sulfate sodium-induced severe colitis in rats. Cell Transplant 24: 2601-2614, 2015.

24. Wang PP, Xie DY, Liang XJ, Peng L, Zhang GL, Ye YN, Xie C and Gao ZL: HGF and direct mesenchymal stem cells contact synergize to inhibit hepatic stellate cells activation through TLR4/NF-kB pathway. PLoS One 7: e43408, 2012.

25. Plumas J, Chaperot L, Richard MJ, Molens JP, Bensa JC and Favrot MC: Mesenchymal stem cells induce apoptosis of activated T cells. Leukemia 19: 1597-1604, 2005

26. Akiyama K, Chen C, Wang D, Xu X, Qu C, Yamaza T, Cai T, Chen W, Sun L and Shi S: Mesenchymal-stem-cell-induced immunoregulation involves FAS-ligand-/FAS-mediated T cell apoptosis. Cell Stem Cell 10: 544-555, 2012.

27. Benvenuto F, Ferrari S, Gerdoni E, Gualandi F, Frassoni F, Pistoia V, Mancardi G and Uccelli A: Human mesenchymal stem cells promote survival of T cells in a quiescent state. Stem Cells 25: 1753-1760, 2007.

28. Ramasamy R, Lam EW, Soeiro I, Tisato V, Bonnet D and Dazzi F: Mesenchymal stem cells inhibit proliferation and apoptosis of tumor cells: Impact on in vivo tumor growth. Leukemia 21: 304-310, 2007

29. Gu YZ, Xue Q, Chen YJ, Yu GH, Qing MD, Shen Y, Wang MY, Shi Q and Zhang XG: Different roles of PD-L1 and FasL in immunomodulation mediated by human placenta-derived mesenchymal stem cells. Hum Immunol 74: 267-276, 2013.

30. Zheng JH, Viacava Follis A, Kriwacki RW and Moldoveanu T: Discoveries and controversies in BCL-2 protein-mediated apoptosis. FEBS J 283: 2690-2700, 2016.

31. Lee SH, Park SW, Pyo CW, Yoo NK, Kim J and Choi SY: Requirement of the JNK-associated Bcl-2 pathway for human lactoferrin-induced apoptosis in the Jurkat leukemia T cell line. Biochimie 91: 102-108, 2009.

32. Kapur SK and Katz AJ: Review of the adipose derived stem cell secretome. Biochimie 95: 2222-2228, 2013.

33. Wang J, Guan E, Roderiquez G and Norcross MA: Synergistic induction of apoptosis in primary CD4(+) T cells by macrophage-tropic HIV-1 and TGF-beta1. J Immunol 167: 3360-3366, 2001.

34. Tan J, Wu W, Xu X, Liao L, Zheng F, Messinger S, Sun X, Chen J, Yang S, Cai J, Gao X, et al: Induction therapy with autologous mesenchymal stem cells in living-related kidney transplants: A randomized controlled trial. JAMA 307: 1169-1177, 2012.

35. Reinders ME, de Fijter JW, Roelofs H, Bajema IM, de Vries DK, Schaapherder AF, Claas FH, van Miert PP, Roelen DL, van Kooten C, et al: Autologous bone marrow-derived mesenchymal stromal cells for the treatment of allograft rejection after renal transplantation: Results of a phase I study. Stem Cells Transl Med 2: 107-111, 2013

36. Peng Y, Ke M, Xu L, Liu L, Chen X, Xia W, Li X, Chen Z, Ma J, Liao D, et al: Donor-derived mesenchymal stem cells combined with low-dose tacrolimus prevent acute rejection after renal transplantation: A clinical pilot study. Transplantation 95: $161-168,2013$.

This work is licensed under a Creative Commons Attribution-NonCommercial-NoDerivatives 4.0 International (CC BY-NC-ND 4.0) License. 